\title{
Embedding Sustainability in Business Modelling through Multi-stakeholder Value Innovation
}

\author{
Samuel W. Short, Padmakshi Rana*, Nancy M.P. Bocken, and Steve Evans \\ University of Cambridge, Institute for Manufacturing \\ 17 Charles Babbage Road, Cambridge CB3 OFS, United Kingdom \\ pr296@cam.ac.uk
}

\begin{abstract}
This paper investigates how businesses might create balanced social, environmental and economic value through integrating sustainability more fully into the core of their business. For this purpose a more systematic approach to business model innovation for sustainability is required. A novel value mapping tool is proposed to help firms create value propositions better suited for sustainability. The tool adopts a multiple stakeholder view of value, a network rather than firm centric perspective, and introduces a novel way of conceptualizing value that specifically introduces value destroyed and value missed, in addition to traditional terms of the core value proposition, and new opportunities for value creation and capture. This will support business modelling for sustainability.
\end{abstract}

Keywords: sustainability, business model, sustainable business model, business model innovation, value creation.

\section{Background}

Current approaches to industrial sustainability such as cleaner production, ecoinnovation, and Corporate Social Responsibility (CSR) are enabling industry to reduce un-sustainability. However, these approaches assume that business can continue largely as usual by simply making incremental efficiency and emissions improvements, or giving a little back to society in the form of philanthropic initiatives to offset negative impacts of business. These efforts increasingly appear inadequate to address the growing challenges facing industry and society of climate change, resource scarcity, environmental degradation, and escalating concerns over social sustainability.

A fundamental paradigm shift appears necessary, in which business activities and consumption patterns are aligned with environmental and social objectives. With careful business model redesign it may be possible for mainstream manufacturers to radically improve sustainable performance to deliver greater environmental and social value while at the same time delivering economic sustainability, as suggested by Stubbs and Cocklin (2008), Porter and Kramer (2011), Yunus et al. (2010), and FORA (2010).

\footnotetext{
* Corresponding author. 


\subsection{Business Models}

A significant number of authors have contributed to the literature on business models and business model innovation. There appears to be reasonably good conceptual understanding, albeit, with several differing perspectives (Teece 2010 and Zott et. al 2011). Richardson (2008), based on a wide range of literature, identifies some common themes, and concisely summarises the elements of business models as: the value proposition (i.e. the offer and the target customer segment), the value creation and delivery system, and the value capture system. Zott and Amit (2010), present the business model from an activity system perspective, and hence view the business model as a network. This exemplifies an emerging view that business models need to be developed with a network rather than firm-centric perspective. Furthermore, Chesbrough and Rosenbloom (2002), Zott and Amit (2010), Teece (2010) and Osterwalder and Pigneur (2010), are key authors who have described a business modelling process.

\subsection{Sustainable Business Model}

A sustainable business model has been defined as 'a business model that creates competitive advantage through superior customer value and contributes to a sustainable development of the company and society' (Lüdeke-Freund 2010). Stubbs and Cocklin (2008) assert that sustainable business models use both a systems and firm-level perspective, build on the triple bottom line approach to define the firm's purpose and measure performance, include a wider range of stakeholders, and consider the environment and society as stakeholders. Sustainable business models as a prerequisite must be economically sustainable. As such, Schaltegger et al. (2011) suggests the objective in business modelling for sustainability is therefore to identify solutions that allow firms to capture economic value from generating public environmental and social value, thereby establishing the business case for sustainability.

\subsection{Value Innovation and Stakeholders}

Business model innovation involves changing 'the way you do business', rather than 'what you do' and must go beyond process and products (Amit and Zott 2012). In other words, business model innovation is about changing the overall value proposition of the firm and reconfiguring the network of stakeholders involved in creating and delivering the value.

At the core of business model innovation is re-thinking the value proposition. Conventionally, business model innovation emphasizes almost exclusively on creating new forms of customer value. To create sustainable business, a more holistic view of the value proposition is required that takes a wider stakeholder perspective (Bowman and Ambrosini 2000), and integrates economic, social and environmental value creation. Hence, the value proposition needs to include benefits to other stakeholders and specifically to society and the environment as well as to customers 
and the firm. Adapting Donaldson and Preston's (1995) view, six stakeholder types can be observed for sustainable business models and modelling - Customers, investors and shareholders, employees, suppliers and partners, the environment, and society. As Allee (2011) suggests, the scope of value needs to be extended in a much more explicit manner that involves understanding tangible and intangible value flows 1 between stakeholders towards identifying relationships, exchanges and interactions, and opportunities for greater shared-value creation.

\subsection{Tools for Business Model Innovation for Sustainability}

Few tools if any really assist firms in the practical creation of business models for sustainability. The tools and methods currently used are either conceptual or have not been used widely in industry, and typically rely on a well-trained (external) facilitator.

One of the seemingly popular frameworks to support the generic business modelling process is Osterwalder and Pigneur's (2010) business model canvas. While being well-conceived and academically grounded its ability to generate innovative thinking beyond pure economic value creation seems limited due to the narrow view of stakeholder value. Network-centric tools for business model innovation are generally still highly conceptual to date. Tools such as Allee's (2011) Value Network Analysis (VNA) offer an approach to value mapping and understanding shared value creation, which might assist in business modelling. However, VNA maps are complicated and time-consuming to develop, and not specifically intended for business modelling.

\section{Practice Review}

Despite the apparent shortfalls in tools and methods, there are an increasing number of practical examples of firms successfully exploring and innovating for sustainability. A practice review was conducted which consisted of the assessment of case studies in the literature and popular press, augmented with in-depth case studies of five firms that are actively engaging in business model innovation for sustainability. The cases were selected to represent a range of industry sectors, and include start-up, small and medium size enterprises (SMEs) and multinational companies (MNCs). These cases range from an incremental approach to sustainability innovation through to firms seeking to introduce radical change. A semi-structured interview approach was adopted to explore how these firms conceptualise business model innovation for sustainability, and how they are seeking to embed sustainability into the core of their businesses. Several common themes emerged from the practice review:

\footnotetext{
${ }^{1}$ Examples of tangible value include products, services, money, knowledge, and technology while intangible values include market access, product feedback, and corporate reputation (Allee 2011).
} 
- A common recognition of the need for innovation to embed sustainability in the business by consciously considering environmental and social value.

- Innovations specifically target negative impacts of business, and seek to reduce losses and waste. This appears somewhat distinct from mainstream business where emphasis is on seeking opportunities for new customer-orientated value creation.

- Innovation has been approached generally in an ad-hoc, incremental, and experimental manner, rather than following a prescriptive process or using specific tools.

- Innovations often depend strongly on visionary leadership of a few key individuals.

- The term 'value' was used often (e.g. customer value, economic value) but there seems to be considerable ambiguity about the use and meaning of the term.

Innovation always presents some level of risk and uncertainty for a firm since it requires going beyond what they currently know and do (Chesbrough 2010). Business model innovation for sustainability seems likely to compound this due to the need to consider additional social and environmental dimensions of value. For this reason, and perhaps because of the lack of systematic tools, business model innovation for sustainability to date has relied on somewhat radical leaders, and has to a large extent been avoided by most mainstream manufacturers.

\section{$3 \quad$ Research Gap}

This paper identifies a need for a tool to assist firms in better understanding sustainable value creation within their business activities, and assist them in developing new business models with sustainability at their core. Specifically, current tools and methods lack a systematic approach for considering value for multiple stakeholders and for innovating the business model for sustainability. In general, a firm-centric approach rather than a network (system) perspective is taken. This paper investigates the following question: How can sustainability be embedded in the business modelling process through a better understanding of value?

\section{Proposed Solution - A Value Mapping Tool}

Based on the above review, a value mapping tool is proposed to help companies create value propositions to support business modelling for sustainability. A pilot test of this tool was conducted with a start-up company to develop the approach. The authors conducted further brainstorming against existing industrial examples to further enhance the tool. As a next stage of the research the tool will be comprehensively tested with a wider range of industrial participants. The novel aspects of this tool to address the gap identified in literature and practice are:

- Systematic assessment of value based on the observation that business model innovation for sustainability not only needs to seek to create new forms of value, but must also seek to address value that is currently destroyed or missed. 
- A network-centric perspective for value innovation to ensure optimisation/consideration of value from a total network, or system-wide perspective, rather than narrowly considering a firm-centric view of value.

- A multiple stakeholder view of value. Current business modelling processes and tools predominantly focus on customers and partners in the immediate value-chain. This process seeks to expand this range of stakeholders.

\subsection{Underlying Rationale for the Proposed Value Mapping Tool}

The basis of the proposed tool for value mapping is the observation (literature and practice) that product/service industrial networks often create a portfolio of opportunities for value innovation for their various stakeholders as illustrated below in figure 1.

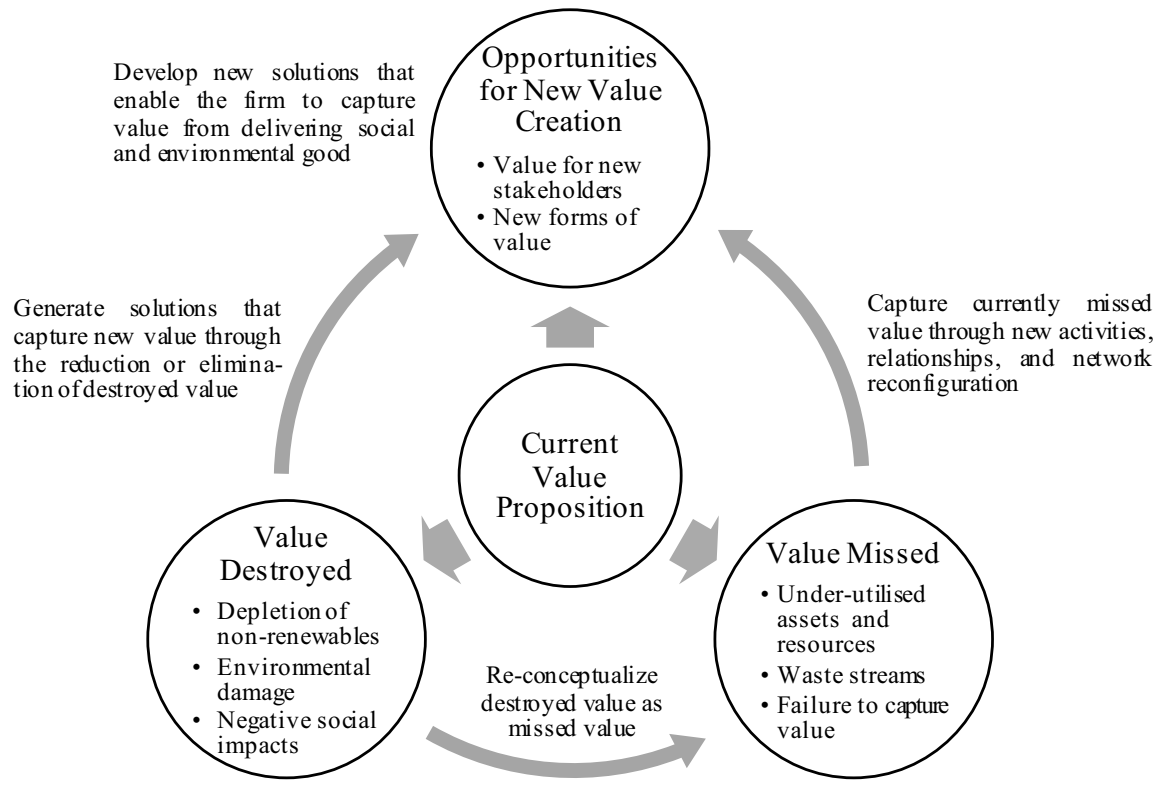

Fig. 1. Opportunities for Value Innovation

At the core of this portfolio is the value proposition of the network. This represents the benefits derived by each stakeholder in the forms of exchange value involved in creating and delivering a product or service offering, and value in use of that product or service (Lepak et al. 2007). In delivering the value proposition, individual stakeholders and networks collectively may also destroy value through their activities. Value destroyed can take various forms, but in the sustainability context is mostly concerning the damaging environmental and social impacts of business activities. The literature often refers to these as negative externalities, but it is felt that this terminology may tend to artificially distance these impacts from the firm. 
Furthermore, networks and individual stakeholders also often squander value within their existing business models. This can be conceived as missed value opportunities, where individual stakeholders fail to capitalise on existing resources and capabilities, are operating below industry best-practice, or fail to receive the benefits they actually seek from the network. This might be due to poorly designed value creation or capture systems, failure to acknowledge the value, or inability to persuade other stakeholders to pay for the benefit. There are also new value opportunities, which tend to be the more usual focus of business model innovation, seeking to expand the business into new markets and introduce new products and services.

\subsection{Value Mapping Tool}

A preliminary tool has been developed to structure the value mapping process as shown in figure 2.

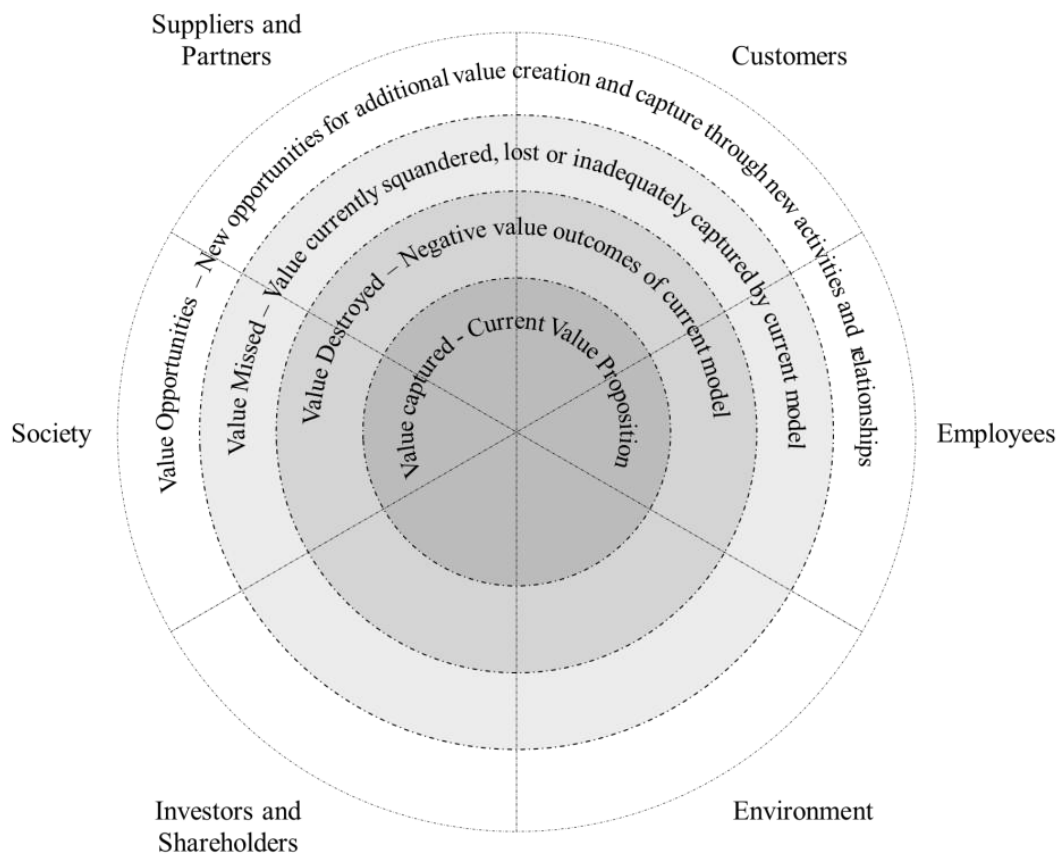

Fig. 2. Value Mapping Tool

The design of the tool is based on emphasising:

- Stakeholder segments. Each segment represents a relevant stakeholder group in the product/service network. To facilitate a network-centric perspective, the firm is represented as employee and owner stakeholder groups, rather than as a discrete stakeholder. 
- Four representations of value. The four circles represent the forms of value that are of specific interest to the process of business modelling for sustainability proposed in figure 1. Identifying them separately encourages a more thorough and complete exploration of the current business model, and assists in identifying areas requiring change or improvement.

The circular form of the tool was developed over a series of workshops, to facilitate a holistic system-perspective of value, to encourage equal consideration of all stakeholder interests, and explore the inter-relatedness between stakeholders. Alternative formats such as tabular data capture were tested, but the circular tool better engaged the participants, facilitated discussion of opportunities for value creation, and better stimulated creative lateral thinking.

\subsection{The Value Mapping Process (Using the Tool)}

The process follows several steps:

- The process begins by defining the unit of analysis as the product/service, or portfolio of products/services offered by a business unit, firm, or an industry. The focus is on the offering, rather than the firm, to support a network perspective.

- Stakeholders are identified and placed in each segment of the tool. The starting point is generic stakeholder types, but the tool is populated with specific stakeholders to facilitate the analysis. Specifically society and the environment are included as stakeholders. In a workshop setting it was observed to be beneficial for some segments to initially be left blank to allow later addition during the process.

- A facilitated brainstorming is then used to populate each stakeholder segment in turn with the various forms of value generated for that stakeholder - starting at the centre of the circle and working outwards. This follows a logical progression from the core value proposition by the current business model, outwards to values further removed from the core offering. By following this progression each step builds upon and is informed by each preceding step as illustrated earlier in figure 1.

To maximise the potential of the tool, representatives or suitable proxies for each major stakeholder group should participate in the process to solicit broad perspectives on value. Furthermore, a lifecycle-based approach is introduced to assist participants in identifying all stakeholders and various forms of value throughout each stage in the provision of the product/service from concept through to end-of-life.

\section{Discussion}

Business model innovation seems a key to delivering future sustainability. This paper identifies a gap in current literature and practice for systematic tools to assist firms in business model innovation for sustainability and hence proposes a tool to assist firms and practitioners in mapping value exchanges for sustainability. The tool is intended as a first step in a business modelling process for embedding sustainability into the core purpose of the firm and its network of stakeholders. 
To further develop business modelling for sustainability, an approach to assist in transforming the value proposition is needed to help eliminate destroyed value or shift destroyed value into positive opportunities; seek solutions to capture missed value; and integrate new opportunities for value creation. It should be reiterated that the purpose of such innovation is not simply to reduce negatives, but rather to reconceive the business model to deliver sustainability. Amit and Zott (2012) suggest this might be achieved through introducing new activities, new stakeholders, or reconfiguring the existing activities and network in novel ways. A potential practical approach to facilitate this innovation process might be through building upon knowledge of existing and proven business model innovations for sustainability to date. Preliminary work has collated several potential business model innovation archetypes, and these are under analysis to identify defining patterns and attributes that might facilitate grouping and provide mechanisms for achieving value proposition innovation. Further work with industrial partners is planned to develop the business modelling process to refine and demonstrate the approach.

Acknowledgements. This paper builds on work undertaken on SustainValue, a European Commission's $7^{\text {th }}$ Framework Programme (FP7/2007-2013). The authors gratefully acknowledge the support of the European Commission, and the contribution of the academic and industrial partners on this project in developing and testing the ideas presented herein.

\section{References}

1. Amit, R., Zott, C.: Creating Value through Business Model Innovation. MIT Sloan Management Review 53(3), 41-49 (2012)

2. Allee, V.: Value Networks and the True Nature of Collaboration, Online edn. Value Net Works and Verna Allee Associates (2011)

3. Bowman, C., Ambrosini, V.: Value Creation versus Value Capture: Towards a Coherent Definition of Value in Strategy. British Journal of Management 11, 1-15 (2000)

4. Chesbrough, H., Rosenbloom, R.S.: The role of the business model in capturing value from innovation: evidence from Xerox Corporation's technology spin-off companies. Industrial and Corporate Change 11(3), 529-555 (2002)

5. Chesbrough, H.: Business Model Innovation: Opportunities and Barriers. Long Range Planning 43(2-3), 354-363 (2010)

6. Donaldson, T., Preston, L.E.: The Stakeholder Theory of the Corporation: Concepts, Evidence, and Implications. The Academy of Management Review 20(1), 65-91 (1995)

7. FORA Nordic project: Green business models in the Nordic Region: A key to promote sustainable growth, Denmark (2010)

8. Lepak, D.P., Smith, K.G., Taylor, M.S.: Value Creation and Value Capture: A Multilevel Perspective. The Academy of Management Review 32(1), 180-194 (2007)

9. Osterwalder, A., Pigneur, Y.: Business Model Generation: A Handbook for Visionaries, Game Changers, and Challengers. John Wiley \& Sons (2010)

10. Porter, M.E., Kramer, M.R.: Creating Shared Value. Harvard Business Review (2011)

11. Richardson, J.: The business model: an integrative framework for strategy execution. Strategic Change 17(5-6), 133-144 (2008) 
12. Schaltegger, S., Lüdeke-Freund, F., Hansen, E.G.: Business Cases for Sustainability and the Role of Business Model Innovation Developing a Conceptual Framework. Centre for Sustainability Management (CSM), Leuphana University of Lueneburg, Lueneburg (2011)

13. Stubbs, W., Cocklin, C.: Conceptualizing a "Sustainability Business Model". Organization \& Environment 21(2), 103-127 (2008)

14. Teece, D.J.: Business Model, Business Strategy and Innovation. Long Range Planning 43, 172-194 (2010)

15. Yunus, M., Moingeon, B., Lehmann-Ortega, L.: Building Social Business Models: Lessons from the Grameen Experience. Long Range Planning 43(2-3), 308-325 (2010)

16. Zott, C., Amit, R., Massa, L.: The Business Model: Recent Developments and Future Research. Journal of Management 37(4), 1019-1042 (2011)

17. Zott, C., Amit, R.: Business Model Design: An Activity System Perspective. Long Range Planning 43(2-3), 216-226 (2010) 